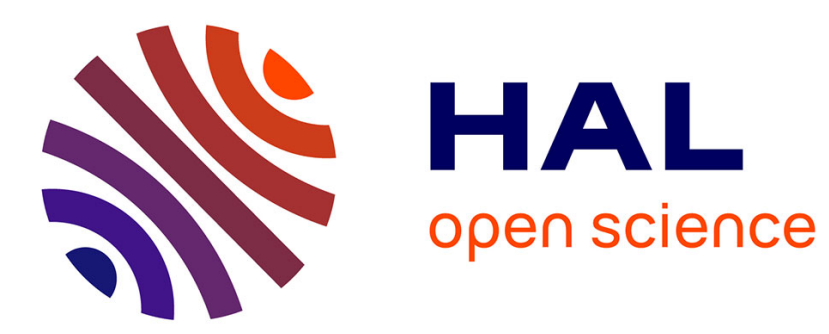

\title{
Influence of Defects on Sub- $\AA$ Optical Linewidths in Eu3+: Y2O3 Particles
}

Karmel de Oliveira Lima, Rogéria Rocha Gonçalves, Domitille Giaume, Alban Ferrier, Philippe Goldner

\section{- To cite this version:}

Karmel de Oliveira Lima, Rogéria Rocha Gonçalves, Domitille Giaume, Alban Ferrier, Philippe Goldner. Influence of Defects on Sub-Å Optical Linewidths in Eu3+: Y2O3 Particles. Journal of Luminescence, 2015, 168, pp.276-282. 10.1016/j.jlumin.2015.08.012 . hal-01198714

\section{HAL Id: hal-01198714 https: / hal.sorbonne-universite.fr/hal-01198714}

Submitted on 14 Sep 2015

HAL is a multi-disciplinary open access archive for the deposit and dissemination of scientific research documents, whether they are published or not. The documents may come from teaching and research institutions in France or abroad, or from public or private research centers.
L'archive ouverte pluridisciplinaire HAL, est destinée au dépôt et à la diffusion de documents scientifiques de niveau recherche, publiés ou non, émanant des établissements d'enseignement et de recherche français ou étrangers, des laboratoires publics ou privés. 


\title{
Influence of Defects on Sub- $\AA$ Optical Linewidths in $\mathrm{Eu}^{3+}: \mathrm{Y}_{2} \mathrm{O}_{3}$ Particles
}

\author{
Karmel de Oliveira Lima, ${ }^{\ddagger}$ Rogéria Rocha Gonçalves ${ }^{\S}$, Domitille Giaume, ${ }^{\ddagger}$ Alban Ferrier ${ }^{\ddagger, t, *}$ \\ and Philippe Goldner, ${ }^{\ddagger *}$
}

${ }^{\ddagger}$ PSL Research University, Chimie ParisTech - CNRS, Institut de Recherche de Chimie Paris, 75005, Paris, France

${ }^{\dagger}$ Sorbonne Universités, UPMC Univ Paris 06, 75005, Paris, France

${ }^{\S}$ Departamento de Química, Faculdade de Filosofia Ciências e Letras de Ribeirão Preto, Universidade de São Paulo, Avenida Bandeirantes, 3900, CEP 14040-901, Ribeirão Preto, SP, Brazil

\section{Corresponding Authors}

*E-mail: alban.ferrier@chimie-paristech.fr

Tel: +33153737935

Fax: +33146347489

* E-mail: philippe.goldner@ chimie-paristech.fr

Tel: +33153737930

Fax: +33146347489

\begin{abstract}
Rare earth doped nanocrystals have been recently suggested as useful materials for applications in quantum information processing. To reach optical properties closer to bulk crystals ones, it is still necessary to reduce the defects that can arise in nanoscale structures. Here, we probe the defects level by monitoring the inhomogeneous broadening of the ${ }^{7} \mathrm{~F}_{0} \rightarrow{ }^{5} \mathrm{D}_{0}$ transition in particles of $0.3 \% \mathrm{Eu}^{3+}: \mathrm{Y}_{2} \mathrm{O}_{3}$. We find that lines as narrow as $14 \mathrm{GHz}(0.015 \mathrm{~nm})$, a value comparable to single crystals, can be obtained in $150 \mathrm{~nm}$ particles calcinated at $1200^{\circ} \mathrm{C}$. The additional broadening observed for particles calcinated at lower temperature is attributed to defects inside crystallites and not to surface effects. A linear correlation is also observed between optical and Raman linewidths, suggesting that both processes are sensitive to the same defects. ${ }^{5} \mathrm{D}_{0}$ excited state lifetimes are well described by a model based on an effective refractive index and we conclude that the defects causing the inhomogeneous broadening have no effect on the excited state population.
\end{abstract}

\section{INTRODUCTION}

Rare earth (RE) doped particles are actively investigated as efficient light emitters for various applications in biology, imaging, lighting or display [1-6]. Recently it was shown that RE nanocrystals could also be useful in quantum information processing (QIP) [7-9] and extend the promising results already obtained in bulk single crystals [10], especially in the field of quantum memories [11-15]. QIP relies on superposition states with long lifetime, corresponding to the so-called coherence lifetime $\left(\mathrm{T}_{2}\right)$. In $\mathrm{Eu}^{3+}: \mathrm{Y}_{2} \mathrm{O}_{3}$ nanocrystals, photon echo measurements showed that $\mathrm{T}_{2}$ can be as long as $3.7 \mu \mathrm{s}$ at $1.3 \mathrm{~K}$ [7] suggesting that these materials could offer new functionalities like coupling to other quantum systems or optical control of single ions $[8,16]$. To achieve this, 
materials still need to be significantly improved, as $T_{2}$ in RE particles is still several orders of magnitude lower than in the best bulk crystals [7, 8]. In particular, defects that may arise at the nanoscale should be reduced. This has been widely studied in fluoride and oxide particles for luminescence based applications [1]. Especially significant improvements in emission and excitation efficiencies have been obtained in $\mathrm{RE}$ doped $\mathrm{Y}_{2} \mathrm{O}_{3}$ particles e.g. by postsynthesis treatments, core-shell structures, co-doping or varying particle and crystallite sizes [17-20].

Superposition states are much more sensitive to perturbations, and their lifetime $T_{2}$ can strongly change in materials with similar excited state lifetimes $\left(\mathrm{T}_{1}\right)$ [21]. Low temperature and high resolution optical spectroscopy is a convenient technique to probe defects at low concentrations, as they cause optical lines to broaden through the variation in the local electric field felt by the optical centers [22]. These defects include impurities, dopants, and vacancies (point defects) as well as various types of dislocations (extended defects). Because of the random nature of defects, each optical center sits in a different environment, resulting in differing optical frequencies. The consequence is the so-called inhomogeneous broadening $\left(\Gamma_{\text {inh }}\right)$ of the transition.

In this paper, we report on the inhomogeneous linewidths of the ${ }^{7} \mathrm{~F}_{0^{-}}{ }^{5} \mathrm{D}_{0}$ transition of sub-micron $\mathrm{Eu}^{3+}: \mathrm{Y}_{2} \mathrm{O}_{3}$ particles in the 10-40 GHz range (0.01-0.04 nm). By independently varying particle and crystallite sizes, we show that defects contributing to $\Gamma_{\text {inh }}$ can be partially removed at high calcination temperatures. These defects are also likely to cause Raman line broadening, as a nearly linear correlation between Raman and optical linewidths is observed. Finally, the variation of ${ }^{5} \mathrm{D}_{0}$ excited state lifetimes as a function of particle size is well described by local field and photon density of states effects. This suggests that the defects have no influence on the relaxation dynamics of the excited state.

\section{EXPERIMENTAL SECTION}

\subsection{Synthesis of $\mathrm{Eu}^{3+}: \mathrm{Y}_{2} \mathrm{O}_{3}$ particles}

We have used $\mathrm{Y}\left(\mathrm{NO}_{3}\right)_{3} \cdot 6 \mathrm{H}_{2} \mathrm{O}\left(99.9 \%\right.$ pure, Alfa Aesar) and $\mathrm{Eu}\left(\mathrm{NO}_{3}\right)_{3} \cdot 6 \mathrm{H}_{2} \mathrm{O}$ (99.99\% pure, Reacton) as yttrium and europium sources. The $\mathrm{Eu}^{3+}$ concentration used for all samples was 0.3 at. \%. In a typical synthesis [23,24], an appropriate amount of urea $\left(\mathrm{CO}\left(\mathrm{NH}_{2}\right)_{2}>99 \%\right.$ pure, Sigma) was dissolved in a mixed Eu/Y aqueous nitrate solution to make a total solution volume of $800 \mathrm{~mL}$. The concentrations varied as $0.3,0.5,2.0$ and $3.0 \mathrm{~mol} . \mathrm{L}^{-1}$ for urea and $7.5 \mathrm{mmol} . \mathrm{L}^{-1}$ for metals $\left(\mathrm{Eu}^{3+}\right.$ and $\left.\mathrm{Y}^{3+}\right)$. The mixed solutions were heated at $85^{\circ} \mathrm{C}$ for $24 \mathrm{~h}$ in a Teflon reactor. The final suspensions were then cooled to ambient conditions and the colloidal particles collected via centrifugation. The wet precipitates were washed with distilled water once to remove the byproducts, then rinsed twice with absolute ethanol, and dried at $80^{\circ} \mathrm{C}$ for $24 \mathrm{~h}$ to yield a white powder. The synthesis yield was $78 \%$ in weight. The 0.3 at. $\% \mathrm{Eu}^{3+}: \mathrm{Y}_{2} \mathrm{O}_{3}$ samples were obtained by calcination of these original powders $\left[\mathrm{Eu}^{3+}\right.$ : $\left.\mathrm{Y}(\mathrm{OH}) \mathrm{CO}_{3} . n \mathrm{H}_{2} \mathrm{O}\right]$ under air during $6 \mathrm{~h}$ at temperatures ranging from 900 to $1200^{\circ} \mathrm{C}$, which were reached using a heating rate of $3{ }^{\circ} \mathrm{C} \min ^{-1}$. The cooling rate was $5{ }^{\circ} \mathrm{C} \min ^{-1}$.

\subsection{Characterization Techniques}

The morphology, size and dispersion of the original and calcinated particles were visualized by transmission electron microscopy (TEM) using a JEOL - JEM-100CXII apparatus at an accelerating voltage of $100 \mathrm{kV}$. For TEM measurements, a small amount of powder was dispersed into anhydrous ethanol, and a drop placed over a carbon coated microscope copper grid. TEM images were used to measure the particle size distributions of each sample, using about 300 particles. The crystalline phase of the annealed systems was determined by x-ray diffraction (XRD) analysis with a PANALYTICAL X'PERT PRO diffractometer using monochromatic CuKa1 radiation (wavelength at $154.060 \mathrm{pm}$ ) in the $2 \theta$ range between 12 and $150^{\circ}$, with a $0.006^{\circ}$ step size at room temperature. The crystallite sizes were determined by Rietveld refinement [25] 
using FullProf software [26]. The integral breadth of all diffractogram peaks between 12 and $150^{\circ}$ were taken into account. Micro-Raman spectra were recorded in the range $100-800 \mathrm{~cm}^{-1}$ using a Renishaw In-via Raman spectrometer with a He-Ne laser excitation (wavelength: $633 \mathrm{~nm}$ ). For optical spectroscopy, the particles, in the form of a powder, were packed into a 2 $\mathrm{mm}$ diameter hole in a $0.5 \mathrm{~mm}$ thick copper plate and held in place by two glass windows. The assembly was put into a closed-cycle cryostat (Janis CTI-Cryogenics Model CCS-150) with the temperature monitored by a LakeShore model 330 controller. The inhomogeneous linewidths were probed by monitoring fluorescence intensity as a function of the frequency of a single mode dye laser (Coherent $899-21,1 \mathrm{MHz}$ linewidth). A low laser intensity $\left(25 \mu \mathrm{W} / \mathrm{cm}^{2}\right.$ ) was used to avoid saturation of the transition and spectral hole burning. Fluorescence was collected by a $75 \mathrm{~mm}$ diameter lens and focused on a photomultiplier tube after suitable filtering to eliminate scattered laser light. Decay measurements were recorded using a tunable optical parametric oscillator pumped by a Nd:YAG Q-switched laser (Ekspla NT342B-SH) with 6 ns pulse length, a Jobin-Yvon HR250 monochromator and a photomultiplier tube. The detection time constant was $20 \mu$ s and data were recorded on a digital oscilloscope.

\section{RESULTS AND DISCUSSION}

\subsection{Structure}

Monodispersed spherical particles with a chemical composition of $\mathrm{Eu}^{3+}$ doped yttrium basic carbonate $\left[\mathrm{Eu}^{3+}: \mathrm{Y}(\mathrm{OH}) \mathrm{CO}_{3} \bullet n\right.$ $\mathrm{H}_{2} \mathrm{O}$ ] were synthesized by homogeneous precipitation [23,24]. In this reaction RE cations precipitate with anions such as $\mathrm{CO}_{3}{ }^{2-}$ and $\mathrm{OH}^{-}$produced by the dissolution of urea and form an amorphous $\mathrm{Y}(\mathrm{OH}) \mathrm{CO}_{3} \cdot n \mathrm{H}_{2} \mathrm{O}$ compound [27]. In order to change the size of these particles the concentration of urea was systematically varied from 0.3 to 3.0 M. Fig. 1 shows a series of histograms and TEM micrographs that illustrate the effect of urea concentration on particle size of $\mathrm{Eu}^{3+}: \mathrm{Y}(\mathrm{OH}) \mathrm{CO}_{3}$. All systems exhibit spherical, well-dispersed particles with smooth surfaces. An increase in urea concentration decreases the average particle size from 729 ([urea]=0.3 M), 633 ([urea]=0.5 M), 289 ([urea]= 2.0 M) to $198 \mathrm{~nm}$ ([urea]= $3.0 \mathrm{M}$ ), with standard deviations of particle sizes around $\pm 73, \pm 67, \pm 39$ and $\pm 38 \mathrm{~nm}$, respectively, according to a log normal fit. The inverse relationship between urea concentration and the average particle size is due to the balance between nucleation and growth processes [27, 28]. At high urea concentration, the elevated amount of $\mathrm{CO}_{3}{ }^{2-}$ and $\mathrm{OH}^{-}$groups promotes a higher degree of super-saturation before the beginning of precipitation. Thus, the larger nucleation density decreases the average particle sizes.
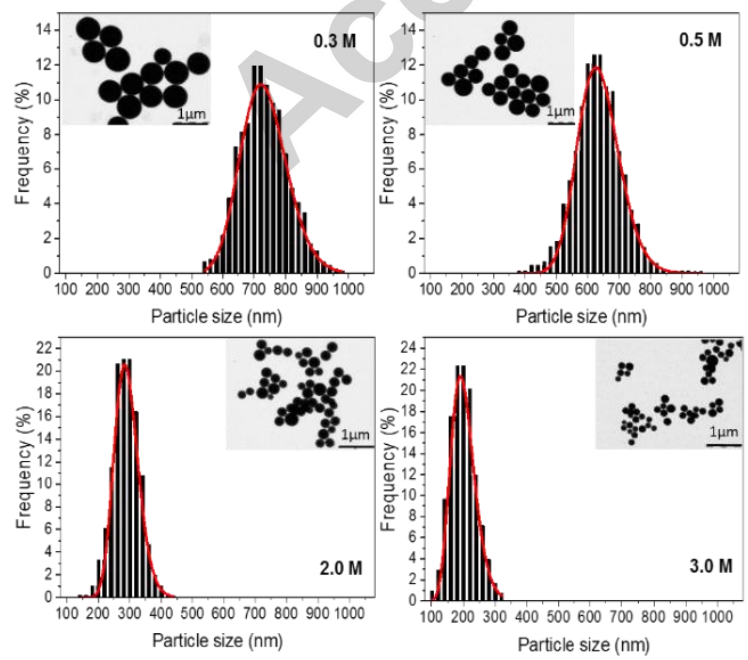
Fig. 1. TEM images and histograms with $\log$ normal fit (red line) of 0.3 at. $\% \mathrm{Eu}^{3+}: \mathrm{Y}(\mathrm{OH}) \mathrm{CO}_{3}$ products obtained using urea concentrations from 0.3 to $3.0 \mathrm{M}$. The scale bars $(1 \mu \mathrm{m})$ are identical in all images.

The yttrium basic carbonate can be decomposed into $\mathrm{Y}_{2} \mathrm{O}_{3}$ at temperatures higher than $600^{\circ} \mathrm{C}$ [23, 27], and in order to obtain yttrium oxide particles, all synthesized systems with different particle sizes were calcinated at $900,1000,1100$ and $1200^{\circ} \mathrm{C}$ during $6 \mathrm{~h}$. The TEM images of systems prepared by using 0.3 and 3.0 $\mathrm{M}$ of urea, and calcinated at 900, 1000, 1100 and $1200^{\circ} \mathrm{C}$ over $6 \mathrm{~h}$ are presented in Fig. 2. The calcination process changes the morphology of the particles as evidenced by the appearance of crystalline planes on the particle surfaces (Fig. 2d and 2h). Micrographs also show that $\mathrm{Y}_{2} \mathrm{O}_{3}$ particles are generally formed by several crystallites that grow when the temperature of calcination is increased. However, single crystalline particles were observed after treatment at $1200^{\circ} \mathrm{C}$ (Fig. 2h) when using $3.0 \mathrm{M}$ of urea. Average particle size as a function of calcination temperature for samples prepared using 0.3 and $3.0 \mathrm{M}$ of urea are shown in Fig. 3.
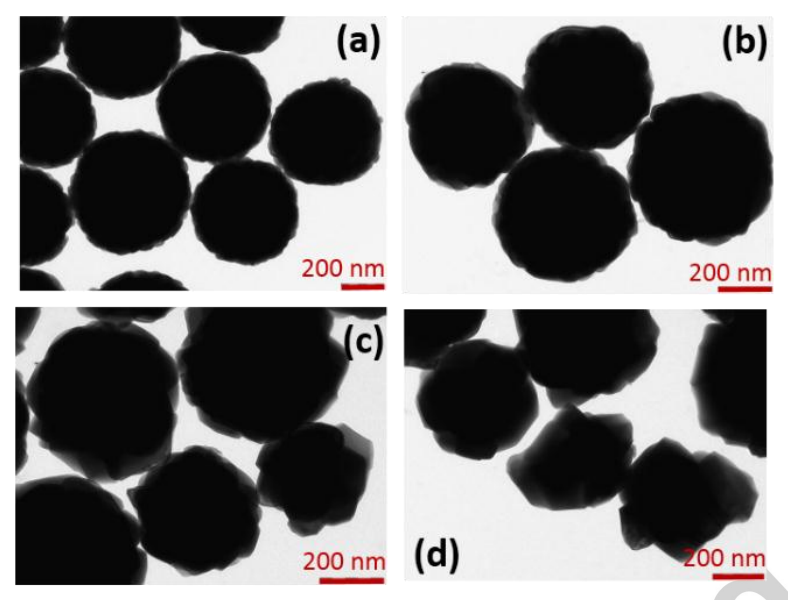

(b)
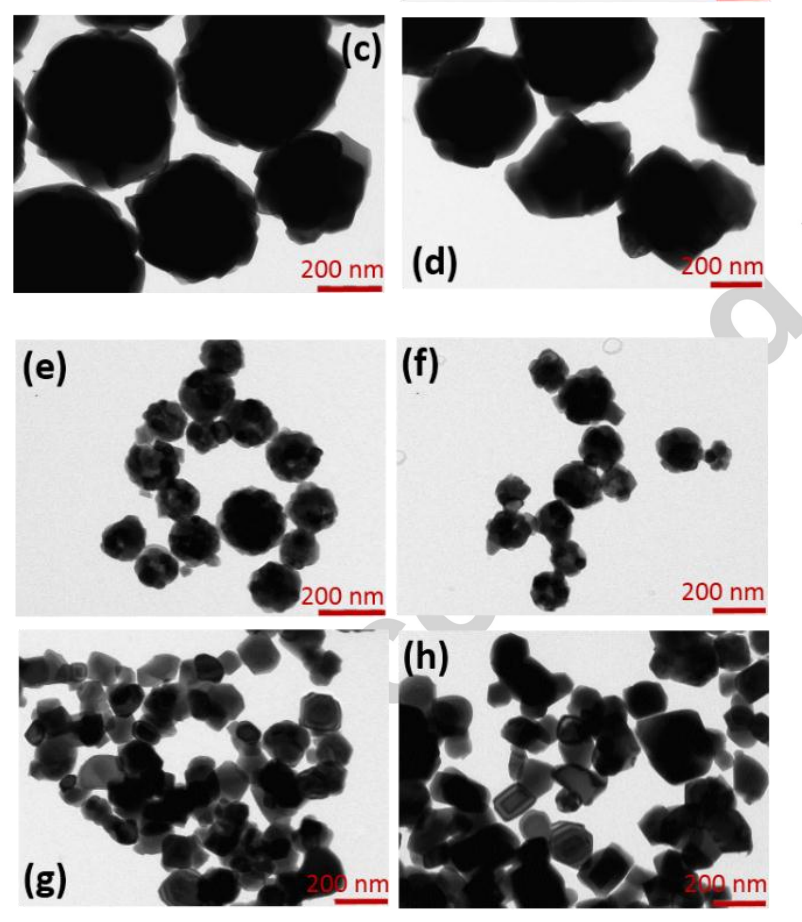

Fig. 2. TEM images of 0.3 at. $\% \mathrm{Eu}^{3+}: \mathrm{Y}_{2} \mathrm{O}_{3}$ particles obtained using $0.3 \mathrm{M}$ of urea and calcinated at (a) 900, (b) 1000, (c) 1100 , (d) $1200{ }^{\circ} \mathrm{C}$, and using $3.0 \mathrm{M}$ of urea and calcinated at (e) 900, (f) 1000 , (g) 1100 , (h) $1200^{\circ} \mathrm{C}$ during $6 \mathrm{~h}$. 


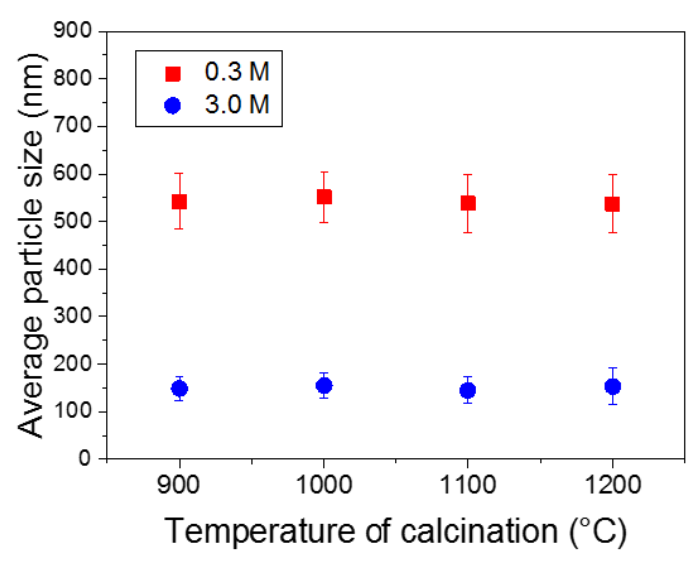

Fig. 3. Average particle size as a function of calcination temperature for 0.3 at. $\% \mathrm{Eu}^{3+}: \mathrm{Y}_{2} \mathrm{O}_{3}$ particles obtained by using 0.3 and 3.0 $\mathrm{M}$ of urea. The error bars are based on the standard deviation of size distributions.

In agreement with previous work $[23,28]$, the $\mathrm{Eu}^{3+}: \mathrm{Y}_{2} \mathrm{O}_{3}$ particles possessed diameters around $25 \%$ smaller compared to the $\mathrm{Eu}^{3+}: \mathrm{Y}(\mathrm{OH}) \mathrm{CO}_{3}$ particles. However, no significant variation in particle size was observed by increasing the temperature of annealing. $\mathrm{Eu}^{3+}: \mathrm{Y}_{2} \mathrm{O}_{3}$ particles show 540, 450, 215 and $150 \mathrm{~nm}$ average diameter sizes and $\pm 58, \pm 48, \pm 34$ and $\pm 30 \mathrm{~nm}$ standard deviations for syntheses using 0.3, 0.5, 2.0 and 3.0 $\mathrm{M}$ of urea, respectively. Fig. 4 presents the XRD patterns of 0.3 at. $\% \mathrm{Eu}^{3+}: \mathrm{Y}_{2} \mathrm{O}_{3}$ particles after calcination at $900,1000,1100$ and $1200{ }^{\circ} \mathrm{C}$ for $6 \mathrm{~h}$, and obtained using $0.5 \mathrm{M}$ of urea. All other samples exhibited the same patterns. They are characteristic of the yttrium europium oxide body-centered cubic (bcc) $\mathrm{Y}_{2} \mathrm{O}_{3}$ structure (Ia3 space group). No additional peaks that could correspond to parasitic phases were found.

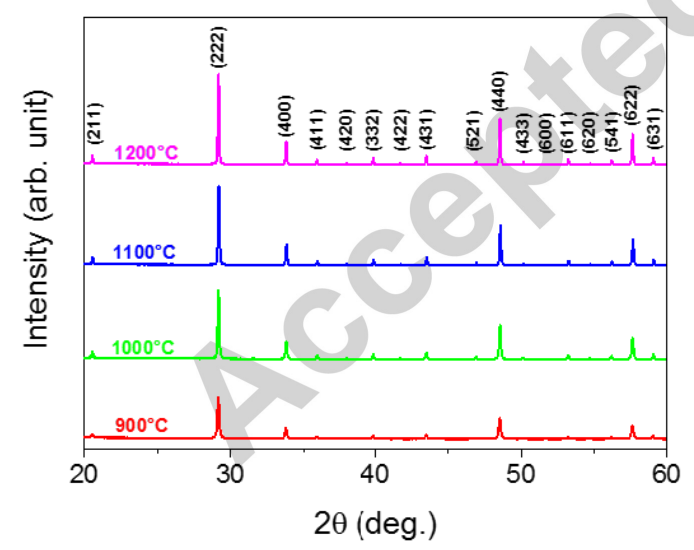

Fig. 4. XRD patterns of 0.3 at. $\% \mathrm{Eu}^{3+}: \mathrm{Y}_{2} \mathrm{O}_{3}$ particles calcinated at $900,1000,1100$ and $1200^{\circ} \mathrm{C}$ and synthesized using 0.5 $M$ of urea.

Average crystallite sizes as a function of calcination temperatures are presented in Fig. 5. A nearly linear enlargement of crystallites with the annealing temperature is found for all systems, in agreement with TEM pictures. Fig. 5 also shows that systems calcinated at the same temperature but with different particle sizes can show different crystallite sizes. 


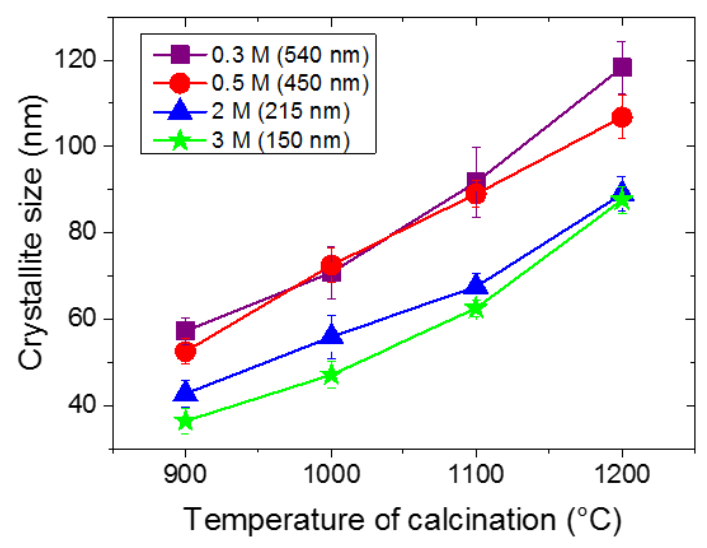

Fig. 5. Crystallite size as a function of temperature of calcination for 0.3 at. $\% \mathrm{Eu}^{3+}: \mathrm{Y}_{2} \mathrm{O}_{3}$ particles synthesized with varying urea concentrations. Average particle sizes are indicated in the legend.

\subsection{Optical Inhomogeneous Linewidths}

Measurements were performed on $\mathrm{Eu}^{3+}{ }^{7} \mathrm{~F}_{0} \rightarrow{ }^{5} \mathrm{D}_{0}$ transition at low temperatures (12 K) to reduce homogeneous broadening to negligible values [29]. $\mathrm{Eu}^{3+}$ ions substitute for $\mathrm{Y}^{3+}$ ones, which occupy two sites in the $\mathrm{Y}_{2} \mathrm{O}_{3}$ cubic structure. We probed $\mathrm{Eu}^{3+}$ ions in the $\mathrm{C}_{2}$ symmetry site, as the absorption corresponding to the other site, of $\mathrm{C}_{3 \mathrm{i}}$ symmetry, is very weak because of inversion symmetry. Linewidths were recorded by monitoring the intensity of the strong ${ }^{5} \mathrm{D}_{0}-{ }^{7} \mathrm{~F}_{2}$ emission at $611 \mathrm{~nm}$, while scanning a single-mode laser centered at $580.88 \mathrm{~nm}$ (vacuum) through the ${ }^{7} \mathrm{~F}_{0} \rightarrow{ }^{5} \mathrm{D}_{0}$ absorption.

Fig. 6 shows the ${ }^{7} \mathrm{~F}_{0} \rightarrow{ }^{5} \mathrm{D}_{0}$ lineshapes obtained for particles using 0.3 and $3.0 \mathrm{M}$ of urea and calcinated at varying temperatures. As in all particles, the lines were centered at a wavelength of $580.88+/-0.01 \mathrm{~nm}$ (vacuum), identical to that found in single crystals and transparent ceramics [30-32]. For both urea concentrations, the inhomogeneous linewidths $\Gamma_{\mathrm{inh}}$ decrease from $35 \mathrm{GHz}(0.04 \mathrm{~nm})$ to about $12 \mathrm{GHz}(0.013 \mathrm{~nm})$ with increasing calcination temperature. At $1200{ }^{\circ} \mathrm{C}, \Gamma_{\text {inh }}=12$ $\mathrm{GHz}$ for the $0.3 \mathrm{M}$ particles of average size $540 \mathrm{~nm}$, a value similar to the one found in a $0.3 \% \mathrm{Eu}^{3+}: \mathrm{Y}_{2} \mathrm{O}_{3}$ single crystal fiber $(11 \mathrm{GHz})$ [30]. Results obtained for other particles are gathered in Fig. 7 and are comparable to values reported for 0.05-0.5 $\% \mathrm{Eu}^{3+}: \mathrm{Y}_{2} \mathrm{O}_{3}$ bulk crystals $(5-23 \mathrm{GHz})[30,31], 0.1 \% \mathrm{Eu}^{3+}$ doped $\mathrm{Y}_{2} \mathrm{O}_{3}$ ceramics $\left(7.8 \mathrm{GHz}\right.$ ) [32], and 0.86 at. $\% \mathrm{Eu}^{3+}$ doped $\mathrm{Y}_{2} \mathrm{O}_{3}$ particles of $5 \mu \mathrm{m}$ containing $60 \mathrm{~nm}$ nanocrystals $(17 \mathrm{GHz})$ [7]. 

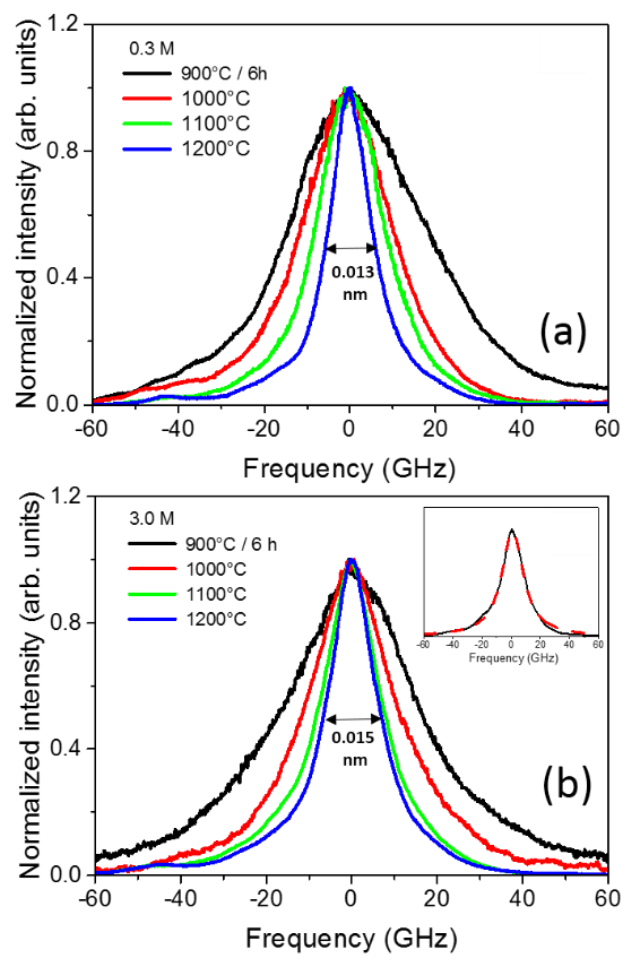

Fig. 6. ${ }^{7} \mathrm{~F}_{0} \rightarrow{ }^{5} \mathrm{D}_{0}$ transition lineshapes obtained by monitoring ${ }^{5} \mathrm{D}_{0}{ }^{-} \mathrm{F}_{2}$ emission at $12 \mathrm{~K}$ in 0.3 at. $\% \mathrm{Eu}^{3+}$ : $\mathrm{Y}_{2} \mathrm{O}_{3}$. Particles synthesized with (a) 0.3 and (b) $3.0 \mathrm{M}$ of urea, and calcinated at temperatures from 900 to $1200^{\circ} \mathrm{C}$. Maxima of all spectra are set at 0 frequency. Inset: Lorentzian fit (dashed line) of the spectrum of the $3.0 \mathrm{M}$ particles calcinated at $1200{ }^{\circ} \mathrm{C}$.

Inhomogeneous linewidths of this magnitude in rare earth doped crystals are generally due to strains produced by defects. Lineshape analysis can differentiate between point and extended defects. In all particles, a Lorentzian lineshape was found, indicating that $\Gamma_{\text {inh }}$ is due to point defects with a low concentration (Fig. 6, inset) [7,22]. A first contribution to point defects comes from $\mathrm{Eu}^{3+}$ ions themselves, partly because of the difference between their ionic radius compared to $\mathrm{Y}^{3+}$ (IR (Eu $\left.{ }^{3+}, \mathrm{VI}\right)$ : $\left.0.950 \square \mathrm{A}, \mathrm{IR}\left(\mathrm{Y}^{3+}, \mathrm{VI}\right): 0.892 \square \mathrm{A}[33]\right)$. We estimate this contribution to be about $6 \mathrm{GHz}$ by comparing $\Gamma_{\text {inh }}$ for single crystals at 0.3 and $0.004 \% \mathrm{Eu}^{3+}$ doping [30]. Fig. 7 shows that in all systems an additional broadening, due to other defects, is observed. This broadening clearly decreases with increasing calcination temperature, but show limited correlation with particle or crystallite size (Fig. 7). For example, 32 to $37 \mathrm{GHz}$ linewidths are found for all particles calcinated at $900{ }^{\circ} \mathrm{C}$, whereas particle and crystallite size vary by a factor 3.6 and 1.5 respectively. With the same size variations, $\Gamma_{\text {inh }}$ stays between 16 and $19 \mathrm{GHz}$ for particles calcinated at $1100{ }^{\circ} \mathrm{C}$. Moreover, for a fixed crystallite size of $60 \mathrm{~nm}, \Gamma_{\text {inh }}$ can vary from 36 to $16 \mathrm{GHz}$. This suggests that the nature of the crystallites' surface and surface/volume ratio has little influence on the inhomogeneous broadening. In particular, for all particles calcinated at $1200{ }^{\circ} \mathrm{C}$, linewidths comparable to those found in single crystal fibers can be obtained [30]. It should also be noted that no strong satellite lines were observed, meaning that most $\mathrm{Eu}^{3+}$ sites are only slightly distorted compared to bulk samples. We therefore conclude that the major contribution to $\Gamma_{\text {inh }}$ besides $\mathrm{Eu}^{3+}$ doping originates from low concentration defects internal to the crystallites. Oxygen vacancies could be one of theses defects. Indeed, they have been suggested as responsible for abnormal temperature variations of the homogeneous linewidths in $\mathrm{Eu}^{3+}: \mathrm{Y}_{2} \mathrm{O}_{3}$ single crystals [30]. The same behavior was found in $\mathrm{Eu}^{3+}: \mathrm{Y}_{2} \mathrm{O}_{3}$ nanocrystals and was also attributed to oxygen vacancies [7]. 


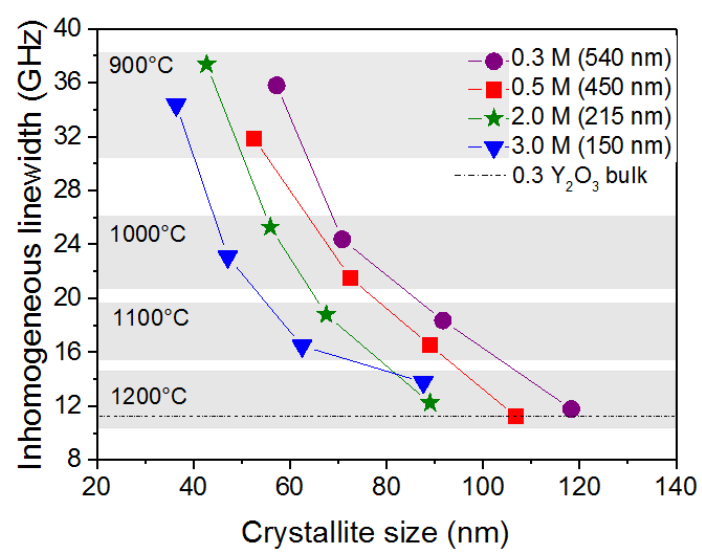

Fig. 7. Inhomogeneous linewidth $\Gamma_{\text {inh }}$ of the ${ }^{7} \mathrm{~F}_{0} \rightarrow{ }^{5} \mathrm{D}_{0}$ transition as a function of crystallite size for $\mathrm{Eu}^{3+}: \mathrm{Y}_{2} \mathrm{O}_{3}$ particles synthesized with varying urea concentrations. Dashed line: $\Gamma_{\text {inh }}$ in a $0.3 \% \mathrm{Eu}^{3+}: \mathrm{Y}_{2} \mathrm{O}_{3}$ single crystal fiber [30]. Average particle sizes are indicated in the legend.

We also performed Raman spectroscopy as vibrational lines are also sensitive to strain, disorder and crystallite size [34, 35]. Fig. 8 shows the Raman spectra of $\mathrm{Eu}^{3+}: \mathrm{Y}_{2} \mathrm{O}_{3}$ particles synthesized using $3.0 \mathrm{M}$ of urea and calcinated at different temperatures. As a reference, the spectrum obtained on a $0.5 \% \mathrm{Eu}^{3+}: \mathrm{Y}_{2} \mathrm{O}_{3}$ transparent ceramic $(50 \mu \mathrm{m}$ of crystallite size) is also presented. All lines could be assigned according to the cubic $\mathrm{Y}_{2} \mathrm{O}_{3}$ space group, in agreement with previous reports [36, 37]. Additional bands were assigned to $\mathrm{Eu}^{3+}$ fluorescence [17] and are marked by asterisks in Figure 8. To compare different particles, we focused on the main line at $377 \mathrm{~cm}^{-1}$. Although it showed no significant frequency shift, a clear decrease of its linewidth with increasing calcination temperature could be observed for particles of different sizes (Fig. 9). As the linewidth shows little correlation with crystallite size, we attribute it to the lattice defects [38], as in the case of the ${ }^{7} \mathrm{~F}_{0} \rightarrow{ }^{5} \mathrm{D}_{0}$ linewidth. Fig. 10 shows that the correlation between the Raman and optical linewidths is nearly linear, except for the smallest particle calcinated at high temperature. This suggests that the same defects, e.g. oxygen vacancies [38], are broadening both Raman and optical lines.

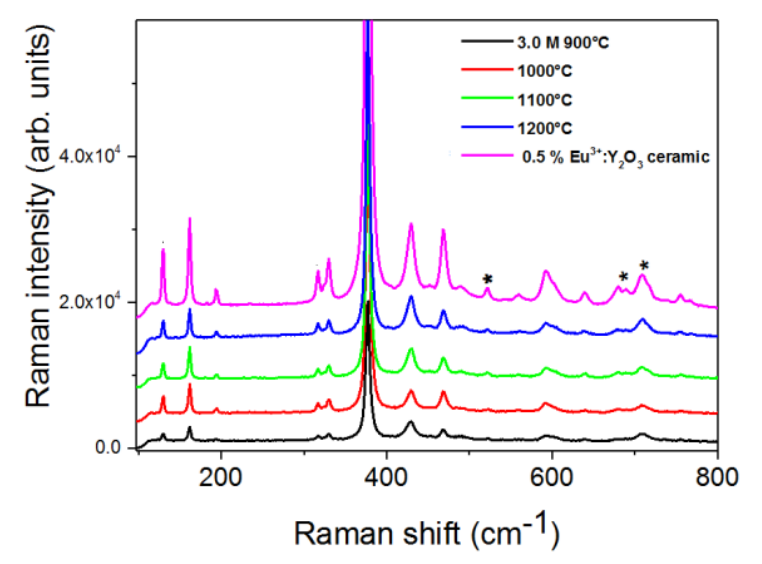

Fig. 8. Raman spectra of 0.3 at. $\% \mathrm{Eu}^{3+}: \mathrm{Y}_{2} \mathrm{O}_{3}$ particles prepared using $3.0 \mathrm{M}$ of urea and calcinated under different temperatures, and of a $0.5 \% \mathrm{Eu}^{3+}: \mathrm{Y}_{2} \mathrm{O}_{3}$ transparent ceramic. Asterisks: $\mathrm{Eu}^{3+}$ fluorescence. 


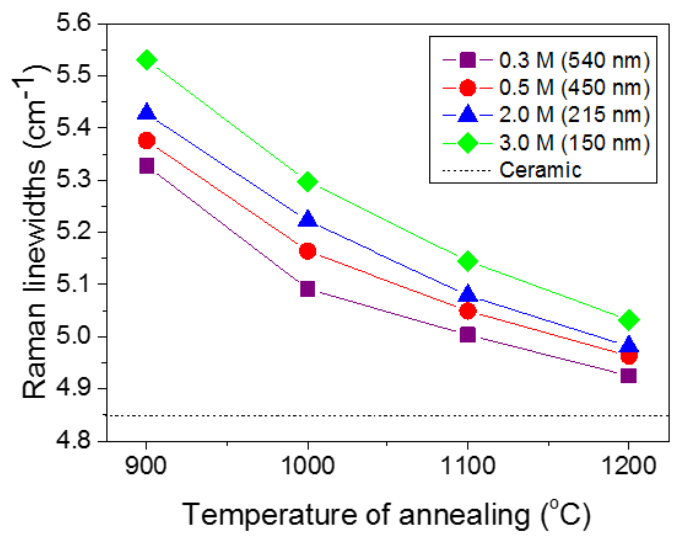

Fig. 9. Linewidth of the main Raman line at $377 \mathrm{~nm}$ as a function of calcination temperature of 0.3 at. $\% \mathrm{Eu}^{3+}: \mathrm{Y}_{2} \mathrm{O}_{3}$ particles synthesized using different urea concentrations. Dashed line: linewidth in a $0.5 \% \mathrm{Eu}^{3+}: \mathrm{Y}_{2} \mathrm{O}_{3}$ transparent ceramic. Average particle sizes are indicated in the legend.

\subsection{Excited State Lifetime}

The defects that broaden the ${ }^{7} \mathrm{~F}_{0} \rightarrow{ }^{5} \mathrm{D}_{0}$ transition may also have dynamical effects by inducing non-radiative relaxations or changing radiative emission probabilities because of site distortion. To investigate this, we recorded the ${ }^{5} \mathrm{D}_{0} \rightarrow{ }^{7} \mathrm{~F}_{2}$ emission decay at $611 \mathrm{~nm}$ after excitation of the ${ }^{7} \mathrm{~F}_{0} \rightarrow{ }^{5} \mathrm{D}_{0}$ transition, at $12 \mathrm{~K}$ and room temperature. In the latter case, particles were in air in the form of a powder or dispersed in water.

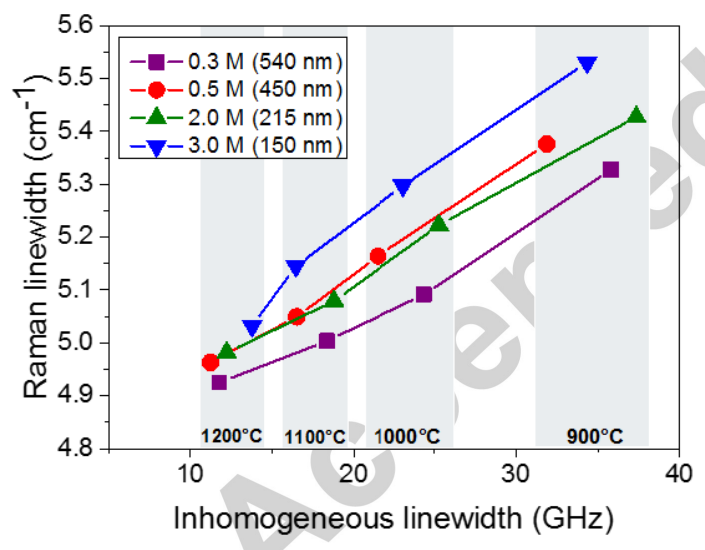

Fig. 10. Linewidth of the main Raman line as a function of the ${ }^{7} \mathrm{~F}_{0} \rightarrow{ }^{5} \mathrm{D}_{0}$ inhomogeneous linewidth in $0.3 \% \mathrm{Eu}^{3+}: \mathrm{Y}_{2} \mathrm{O}_{3}$ synthesized using varying urea concentrations and calcinated at different temperatures. Average particle sizes are indicated in the legend.

All decays could be well fitted by single exponentials and showed no evidence of energy transfers. This was expected as the ${ }^{5} \mathrm{D}_{0}$ level is separated by $12000 \mathrm{~cm}^{-1}$ from the ${ }^{7} \mathrm{~F}_{6}$ one, making it largely insensitive to relaxations by radicals (e.g. $\left.\mathrm{OH}^{-}\right)$that can be present at the particles surface. Moreover, the low doping concentration prevented strong resonant energy transfer between $\mathrm{Eu}^{3+}$ ions. For all particles, room and low temperature decays were identical, which also suggests that the non- 
radiative relaxations from the ${ }^{5} \mathrm{D}_{0}$ level are negligible. However, the lifetimes significantly varied as a function of particle size and temperature of calcination, as shown in Fig. 11.
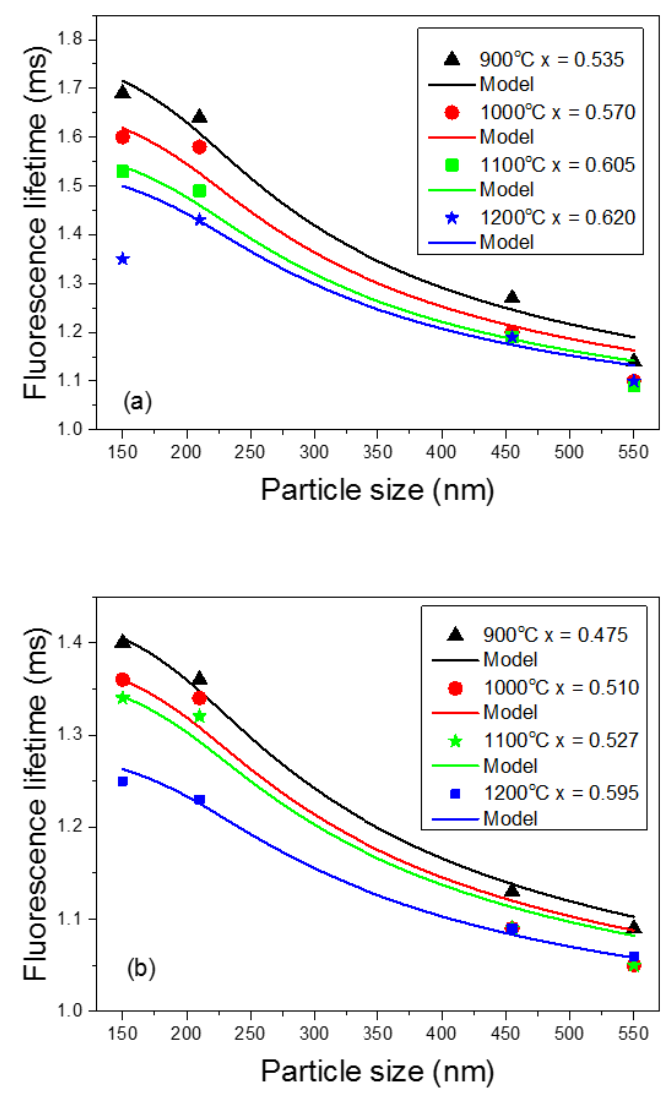

Fig. 11. Lifetimes of the ${ }^{5} \mathrm{D}_{0}$ level measured in air (a) and water (b) as a function of particle size in $0.3 \% \mathrm{Eu}^{3+}: \mathrm{Y}_{2} \mathrm{O}_{3}$ synthesized using varying urea concentrations and calcinated at different temperatures. Solid lines: fit using an effective index based model; $\mathrm{x}$ : filling factor (see text).

${ }^{5} \mathrm{D}_{0}$ lifetimes measured in air varied from $1.08 \mathrm{~ms}$ in the largest particles $(540 \mathrm{~nm})$ calcinated at $1200{ }^{\circ} \mathrm{C}$, to $1.7 \mathrm{~ms}$ in the smallest ones $(150 \mathrm{~nm})$ treated at $900{ }^{\circ} \mathrm{C}$. This effect could be solely due to changes in the photon density of states and local electric field in the particles. This has been reported in many rare earth doped systems [39-42]. When the particles are much smaller than the wavelength of light, radiative transitions probabilities are expressed as a function of an effective index, which is a weighted average between the surrounding medium and bulk crystal indices [39]. In our case, the largest particles have a size comparable to the emission wavelength $(\lambda=611 \mathrm{~nm})$, while the recorded lifetimes are still longer $(1.08 \mathrm{~ms})$ than those of a ceramic with $50 \mu \mathrm{m}$ crystallites $(934 \mu \mathrm{s})$. On the other hand, the smallest particles have a size of $150 \mathrm{~nm}$ which is about $\lambda / 4$ and thus not negligibly small. Hence, models applying to size $<<\lambda[39,43-45]$ do not apply directly and were indeed unable to reproduce our results. To explain our observations, we first make the assumption that each particle is spherical (radius R) and surrounded by the medium (air or water) and other identical particles. This is described by the socalled filling factor $\mathrm{x}$, equal to the volume ratio between the particles and the medium [39]. We take $\mathrm{x}$ as independent of the particle size for a given calcination temperature. When calcination temperature increases, agglomeration, and therefore $\mathrm{x}$, may increase. A particle is therefore surrounded by a medium of index $n_{M}=x n_{B}+(1-x) n$, where $n_{B}=1.91$ is the $Y_{2} O_{3}$ bulk 
refractive index and $\mathrm{n}=1$ for air and 1.33 for water. In a given particle, each $\mathrm{Eu}^{3+}$ ion is placed at the center of a sphere of influence (radius $R_{i}$ ) in which an average index $n_{a}$ is calculated by solving the equation [46,47]:

$$
f_{M} \frac{\varepsilon_{M}-\varepsilon_{a}}{\varepsilon_{M}+2 \varepsilon_{a}}+f_{B} \frac{\varepsilon_{B}-\varepsilon_{a}}{\varepsilon_{B}+2 \varepsilon_{a}}=0
$$

where $\varepsilon_{i}=\varepsilon_{0} n_{i}{ }^{2}$ is the dielectric permittivity corresponding to the refractive index $n_{\mathrm{i}} \cdot \mathrm{f}_{\mathrm{M}}$ and $\mathrm{f}_{\mathrm{B}}=1-\mathrm{f}_{\mathrm{M}}$ are the fractions (in volume) of the sphere of influence occupied by the surrounding medium (index $n_{M}$ ) and the particle (index $n_{B}$ ). They depend on $\mathrm{R}_{\mathrm{i}}, \mathrm{R}$ and the distance of the ion from the center of the particle. For particles of diameter larger than $\mathrm{R}_{\mathrm{i}}$, ions closer to the surface of the particle are therefore in regions of lower index than those at the center of the particle. This average index $n_{a}$ is then used to compute the lifetime $\tau$ of the emitter using the empty cavity model [43]:

$$
\tau=\tau_{0} \frac{1}{n_{a}\left(\frac{3 n_{a}{ }^{2}}{2 n_{a}{ }^{2}+1}\right)^{2}}
$$

where $\tau_{0}$ is the emitter lifetime in vacuum. Finally lifetimes for all emitters in the particle are averaged to give a single value that can be compared to the experimental decay times. First, they were fitted by leaving $R_{i}$ and $x$ free and we found that $R_{i}$ was nearly constant for all data. It was then fixed to $R_{i}=203 \mathrm{~nm}$ and only $x$ was adjustable to generate the curves shown in Figure 11 (each curve corresponds to a single value of $\mathrm{x}$ ). A reasonable agreement is observed, both with absolute values and general shape of the experimental data variations. Only the lifetime measured in air for the $150 \mathrm{~nm}$ particles calcinated at $1200{ }^{\circ} \mathrm{C}$ does not follow the general trend. This could be due to an increased agglomeration. The value of $R_{i}$ is close to the one given in Ref. $46\left(\mathrm{R}_{\mathrm{i}}=150 \mathrm{~nm}\right)$ and $\mathrm{x}$ ranges from 0.47 to 0.62 , corresponding to moderate packing. As expected, $\mathrm{x}$ increases with calcination temperature and in air compared to water. This analysis shows that a simple model based on an effective refractive index can reproduce the experimental lifetime variations. Together with the single exponential fluorescence decays and their lack of temperature dependence, we conclude that the defects causing additional inhomogeneous broadening of the ${ }^{7} \mathrm{~F}_{0} \rightarrow{ }^{5} \mathrm{D}_{0}$ transition in some particles have a negligible effect on the ${ }^{5} \mathrm{D}_{0}$ level excited state dynamics.

\section{CONCLUSIONS}

Monodispersed particles of $0.3 \% \mathrm{Eu}^{3+}: \mathrm{Y}_{2} \mathrm{O}_{3}$ have been synthesized with sizes between 150 and $540 \mathrm{~nm}$. Varying the calcination temperature of the amorphous precursor from 900 to $1200{ }^{\circ} \mathrm{C}$ allowed us to independently vary the crystallite size from 40-60 nm to 90-120 nm. The inhomogeneous linewidths of $\mathrm{Eu}^{3+}{ }^{7} \mathrm{~F}_{0} \rightarrow{ }^{5} \mathrm{D}_{0}$ transition were measured by high-resolution laser spectroscopy and vary between 38 and $12 \mathrm{GHz}$, in the range of single crystals and transparent ceramics at the same $\mathrm{Eu}^{3+}$ concentration. Whereas the particles calcinated at $1200{ }^{\circ} \mathrm{C}$ show an inhomogeneous broadening close to single crystals even for size as low as $150 \mathrm{~nm}$, other particles exhibit an additional broadening independent on particle or crystallite size. We attribute it to point defects, like oxygen vacancies, the concentration of which is reduced by increasing calcination temperature. A nearly linear correlation was also observed in the particles between optical and Raman linewidths, suggesting a common origin. Finally, the influence of these defects on the ${ }^{5} \mathrm{D}_{0}$ excited state lifetime was investigated. Although we observed a strong dependence of lifetimes as a function of particle size, experimental data could be reproduced by a model based on an effective refractive index. We conclude that these defects have a negligible effect on dynamical properties of ${ }^{5} \mathrm{D}_{\mathrm{o}}$ 
population. Further studies, based on photon echoes and time resolved spectra hole burning, are in progress to evaluate their

effects on coherence lifetimes of the ${ }^{7} \mathrm{~F}_{0} \rightarrow{ }^{5} \mathrm{D}_{0}$ transition.

\section{ACKNOWLEDGMENT}

We thank Dr. John Bartholomew and Dr. Nathalie Kunkel for useful comments. The research leading to these results has received funding from the European Union's Seventh Framework Programme FP7/2007-2013/ under REA grant agreements No. 287252 (CIPRIS, People Programme-Marie Curie Actions) and ANR project RAMACO (12-BS08-0015-01).

\section{REFERENCES}

[1] S. Gai, C. Li, P. Yang, J. Lin, Chem. Rev. 114 (2014) 2343-2389.

[2] H. A. Höppe, Angew., Chem. Int. Ed. 48 (2009) 3572-3582.

[3] G. K. Das, T. T. Y. Tan, J. Phys. Chem. C 112 (2008) 11211-11217.

[4] Q. Dai, M. E. Foley, C. J. Breshike, A. Lita, G. F. Strouse, J. Am. Chem. Soc. 133 (2011) 15475-15486.

[5] J. Silver, R. Withnall, A. Lipman, T. G. Ireland, G. R. Fern, J. Lumin. 122-123 (2007) 562-566.

[6] A. Benayas, B. del Rosa, A. Perez-Delgado, K. Santacruz-Gomez, D. Jaque, G. A. Hirata, F. Vetrone, Adv. Optical Mater. 3 (2015) 687-694.

[7] A. Perrot, P. Goldner,D. Giaume, M. Lovrić, C. Andriamiadamanana; R. R. Goncalves, A. Ferrier, Phys. Rev. Lett. 111 (2013) 203601.

[8] T. Utikal, E. Eichhammer, L. Petersen, A. Renn, S. Götzinger, V. Sandoghdar, Nat. Commun. 5 (2014) 3627.

[9] R. Kolesov, K. Xia, R. Reuter, R. Stöhr, A. Zappe, J. Meijer, P. R. Hemmer, J. Wrachtrup, Nat. Commun. 3 (2012) 1029.

[10] P. Goldner, A. Ferrier, O. Guillot-Noël, In Handbook on the Physics and Chemistry of Rare Earths Volume 46; J.-C. G. Bünzli,; V. K.Pecharsky (Eds.), Elsevier, Amsterdam, 2015, pp. 1-78.

[11] F. Bussières, C. Clausen, A. Tiranov, B. Korzh, V. B. Verma, S. W. Nam, F. Marsili, A. Ferrier, P. Goldner, H. Herrmann, C. Silberhorn, W. Sohler, M. Afzelius, N. Gisin, Nat. Photonics 8 (2014) 775-778.

[12] M. P. Hedges, J. J. Longdell, Y. Li, M. J. Sellars, Nature 465 (2010) 1052-1056.

[13] G. Heinze, C. Hubrich, T. Halfmann, Phys. Rev. Lett. 111 (2013) 033601.

[14] M. Lovrić, D. Suter, A. Ferrier, P. Goldner, Phys. Rev. Lett. 111 (2013) 020503.

[15] G. Wolfowicz, H. Maier-Flaig, R. Marino, A. Ferrier, H. Vezin, J. J. L. Morton, P. Goldner, Phys. Rev. Lett. 114 (2015) 170503.

[16] P. Siyushev, K. Xia, R. Reuter, M. Jamali, N. Zhao, N. Yang, C. Duan, N. Kukharchyk, A. D. Wieck, R. Kolesov, J. Wrachtrup, Nat. Commun. 5 (2014) 3895.

[17] W. Wang, W. Widiyastuti, T. Ogi, I. W. Lenggoro, K. Okuyama, Chem. Mater. 19 (2007) 1723-1730.

[18] J. Li, X. Li, X. Sun, T. Ishigaki, J. Phys. Chem. C 112 (2008) 11707-11716.

[19] J. A. Dorman, J. H. Choi, G. Kuzmanich, J. P. Chang, J. Phys. Chem. C 116 (2012) 10333-10340.

[20] R. H. Krishna, B. M. Nagabhushana, H. Nagabhushana, N. S. Murthy, S. C. Sharma, C. Shivakumara, R. P. S. Chakradhar, J. Phys. Chem. C. 117 (2013) 1915-1924.

[21] G. P. Flinn, K. W. Jang, J. Ganem, M. L. Jones, R. S. Meltzer, Phys. Rev. B 49 (1994) 5821-5827.

[22] A. M. Stoneham, Rev. Mod. Phys. 41 (1969) 82.

[23] B. Aiken, W. P. Hsu, E. Matijević, J. Am. Ceram. Soc. 71 (1988) 845-853.

[24] D. Sordelet, M. Akinc, J. Colloid Interf. Sci. 122 (1988) 47-59.

[25] H. M. Rietveld, J. Appl. Cryst. 2 (1969) 65-71.

[26] J. Rodriguez-Carvajal , T. Roisnel, Mater. Sci. Forum 443 (2004) 123-126.

[27] H. Giesche, E. Matijević, J. Mater. Res. 9 (1994) 436-450.

[28] S. Sohn, Y. Kwon, Y. Kim, D. Kim, Powder Technol. 142 (2004) 136-153.

[29] H. S. Yang, K. S. Hong, S. P. Feofilov, B. M. Tissue, R. S. Meltzer, W. M. Dennis, J. Lumin. 83-84 (1999) 139-145.

[30] G. P. Flinn, K. W. Jang, J. Ganem, M. L. Jones, R. S. Meltzer, Phys. Rev. B 49 (1994) 5821-5827.

[31] M. J. Sellars, R. S. Meltzer, P. T. H. Fisk, N. B. Manson, J. Opt. Soc. Am. B 11 (1994) 1468-1473.

[32] A. Ferrier, C. W. Thiel, B. Tumino, M. O. Ramirez, L. E. Bausá, R. L. Cone, A. Ikessue and Ph. Goldner, Phys. Rev. B 87 (2013) 041102.

[33] R. D. Shannon, C. T. Prewitt, Acta Crystallogr B 25 (1969) 925-946.

[34] P. Parayanthal, F. H. Pollak, Phys. Rev. Lett. 52 (1984) 1822-1825.

[35] J. E. Spanier, R. D. Robinson, F. Zhang, S.-W. Chan, I. P. Herman, Phys. Rev. B 64 (2001) 245407.

[36] Y. Repelin, C. Proust, E. Husson, J. M. Beny, J. Solid State Chem. 118 (1995) 163-169.

[37] V. V. Osipov, V. I. Solomonov, A. V. Spirina, E. G. Vovkotrub, V. N. Strekalovskii, Opt. Spectrosc. 116 (2014) 946955. 
[38] I. Kosacki, T. Suzuki, H. U. Anderson, P. Colomban, Solid State Ionics 149 (2002) 99-105.

[39] R. S. Meltzer, S. P. Feofilov, B. M. Tissue, H. B. Yuan, Phys. Rev. B. 60 (1999) R14012-14015.

[40] H. Christensen, D. Gabbe, H. Jenssen, Phys. Rev. B 25 (1982) 1467-1473.

[41] H. Schniepp, V. Sandoghdar, Phys. Rev. Lett. 89 (2002) 257403.

[42] J. C. Boyer, F. Vetrone, J. A. Capobianco, A. Speghini, M. Bettinelli, J. Phys. Chem. B 108 (2004) 20137-20143.

[43] C.-K. Duan, M. F. Reid, Z. Wang, Phys. Lett. A 343 (2005) 474-480.

[44] P. de Vries A. Lagendijk, Phys. Rev. Lett. 81 (1998) 1381-1384.

[45] K. K. Pukhov, T. T. Basiev, Yu. V. Orlovskii, JETP Lett. 88 (2008) 12-18.

[46] V. LeBihan, A. Pillonnet, D. Amans, G. Ledoux, O. Marty, C. Dujardin, Phys. Rev. B 78 (2008) 113405.

[47] D. E. Aspnes, Am. J. Phys. 50 (1982) 704-709.

\section{FIGURE CAPTIONS}

Fig. 1. TEM images and histograms with log normal fit (red line) of 0.3 at. $\% \mathrm{Eu}^{3+}: \mathrm{Y}(\mathrm{OH}) \mathrm{CO}_{3}$ products obtained using urea concentrations from 0.3 to $3.0 \mathrm{M}$. The scale bars $(1 \mu \mathrm{m})$ are identical in all images.

Fig. 2. TEM images of 0.3 at. $\% \mathrm{Eu}^{3+}: \mathrm{Y}_{2} \mathrm{O}_{3}$ particles obtained using $0.3 \mathrm{M}$ of urea and calcinated at (a) 900 , (b) 1000 , (c) 1100, (d) $1200^{\circ} \mathrm{C}$, and using $3.0 \mathrm{M}$ of urea and calcinated at (e) 900 , (f) 1000 , (g) 1100 , (h) $1200^{\circ} \mathrm{C}$ during $6 \mathrm{~h}$.

Fig. 3. Average particle size as a function of calcination temperature for 0.3 at. $\% \mathrm{Eu}^{3+}: \mathrm{Y}_{2} \mathrm{O}_{3}$ particles obtained by using 0.3 and 3.0 $\mathrm{M}$ of urea. The error bars are based on the standard deviation of size distributions.

Fig. 4. XRD patterns of 0.3 at. $\% \mathrm{Eu}^{3+}: \mathrm{Y}_{2} \mathrm{O}_{3}$ particles calcinated at $900,1000,1100$ and $1200^{\circ} \mathrm{C}$ and synthesized using 0.5 M of urea.

Fig. 5. Crystallite size as a function of temperature of calcination for 0.3 at. $\% \mathrm{Eu}^{3+}: \mathrm{Y}_{2} \mathrm{O}_{3}$ particles synthesized with varying urea concentrations. Average particle sizes are indicated in the legend.

Fig. 6. ${ }^{7} \mathrm{~F}_{0} \rightarrow{ }^{5} \mathrm{D}_{0}$ transition lineshapes obtained by monitoring ${ }^{5} \mathrm{D}_{0}{ }^{7} \mathrm{~F}_{2}$ emission at $12 \mathrm{~K}$ in 0.3 at. \% Eu ${ }^{3+}: \mathrm{Y}_{2} \mathrm{O}_{3}$. Particles synthesized with (a) 0.3 and (b) $3.0 \mathrm{M}$ of urea, and calcinated at temperatures from 900 to $1200^{\circ} \mathrm{C}$. Maxima of all spectra are set at 0 frequency. Inset: Lorentzian fit (dashed line) of the spectrum of the $3.0 \mathrm{M}$ particles calcinated at $1200{ }^{\circ} \mathrm{C}$.

Fig. 7. Inhomogeneous linewidth $\Gamma_{\text {inh }}$ of the ${ }^{7} \mathrm{~F}_{0} \rightarrow{ }^{5} \mathrm{D}_{0}$ transition as a function of crystallite size for $\mathrm{Eu}^{3+}: \mathrm{Y}_{2} \mathrm{O}_{3}$ particles synthesized with varying urea concentrations. Dashed line: $\Gamma_{\text {inh }}$ in a $0.3 \% \mathrm{Eu}^{3+}: \mathrm{Y}_{2} \mathrm{O}_{3}$ single crystal fiber [30].

Fig. 8. Raman spectra of 0.3 at. $\% \mathrm{Eu}^{3+}: \mathrm{Y}_{2} \mathrm{O}_{3}$ particles prepared using $3.0 \mathrm{M}$ of urea and calcinated under different temperatures, and of a $0.5 \% \mathrm{Eu}^{3+}: \mathrm{Y}_{2} \mathrm{O}_{3}$ transparent ceramic. Asterisks: $\mathrm{Eu}^{3+}$ fluorescence.

Fig. 9. Linewidth of the main Raman line at $377 \mathrm{~nm}$ as a function of calcination temperature of 0.3 at. $\% \mathrm{Eu}^{3+}: \mathrm{Y}_{2} \mathrm{O}_{3}$ particles synthesized using different urea concentrations. Dashed line: linewidth in a $0.5 \% \mathrm{Eu}^{3+}: \mathrm{Y}_{2} \mathrm{O}_{3}$ transparent ceramic. 
Fig. 10. Linewidth of the main Raman line as a function of the ${ }^{7} \mathrm{~F}_{0} \rightarrow{ }^{5} \mathrm{D}_{0}$ inhomogeneous linewidth in $0.3 \% \mathrm{Eu}^{3+}: \mathrm{Y}_{2} \mathrm{O}_{3}$ synthesized using varying urea concentrations and calcinated at different temperatures.

Fig. 11. Lifetimes of the ${ }^{5} \mathrm{D}_{0}$ level measured in air (a) and water (b) as a function of particle size in $0.3 \% \mathrm{Eu}^{3+}: \mathrm{Y}_{2} \mathrm{O}_{3}$ synthesized using varying urea concentrations and calcinated at different temperatures. Solid lines: fit using an effective index based model;

$\mathrm{x}:$ filling factor

(see text) 